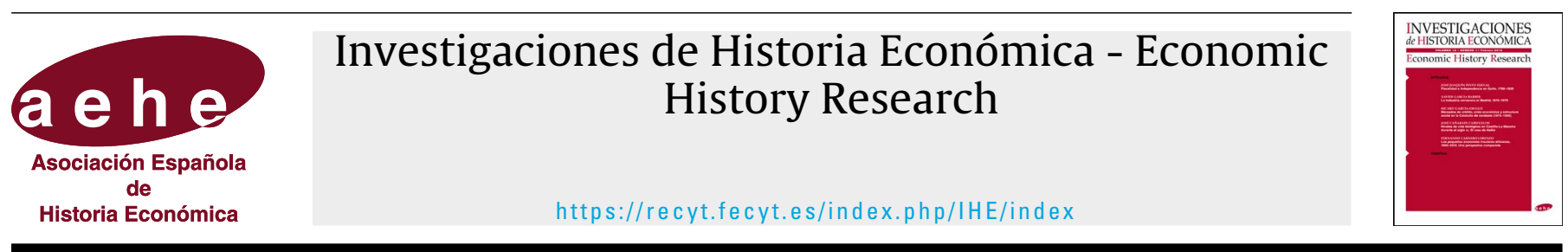

Artículo

\title{
De la gripe de 1918-1919 a las epidemias de poliomielitis en España. Estancias internacionales de investigación en el proceso de modernización científico-sanitario
}

\section{María Isabel Porras Gallo* D \\ Universidad de Castilla-La Mancha}

\section{INFORMACIÓN DEL ARTÍCULO}

\section{Historia del artículo:}

Recibido: 15 de febrero de 2021

Aceptado: 15 de marzo de 2021

On-line: 12 de abril de 2021

\section{Códigos JEL:}

I18

I12

I23

I00

Palabras clave:

Pandemia de gripe de 1918-1919

Epidemias de poliomielitis

Formación bacteriológica y virológica

Estancias de investigación

\begin{abstract}
R E S U M E N
Este trabajo traza un breve recorrido sobre el impacto de la gripe de 1918-1919 y las epidemias de poliomielitis y las respuestas dadas para mostrar cómo estos acontecimientos fueron retos y oportunidades para visibilizar el papel que los profesionales sanitarios especializados en bacteriología y, luego, en virología, en centros internacionales podían desempeñar, y el lugar que los nuevos recursos profilácticos y terapéuticos -sueros y vacunas- ocuparían en ese nuevo enfoque. Con fuentes médico-científicas, legislativas, una selección de prensa general, documentación archivística e impresa de la OMS, desde la historia social de la medicina y, particularmente, de la historia de la enfermedad, se pone de manifiesto el protagonismo que la formación conseguida por los profesionales sanitarios en centros internacionales de investigación, tuvo en la gestión de ambos sucesos epidémicos, en la modernización científico-sanitaria española antes de la Guerra Civil y en la reconstrucción posterior tras la contienda.
\end{abstract}

(C) 2021 Asociación Española de Historia Económica

\section{JEL classification:}

$\mathrm{I} 18$

I12

I23

I00

\section{Keywords:}

Influenza pandemic of 1918-1919

Poliomyelitis epidemics

Bacteriological and virological training Research visits

\section{From the influenza of 1918-1919 to the poliomyelitis epidemics in Spain. International research visits in the process of scientific-sanitary modernisation}

\section{A B S T R A C T}

This paper gives a brief overview of the impact of the 1918-1919 flu and the polio epidemics and the responses to them, to show how they were a challenge and also an opportunity to draw attention to the role that could be played by health professionals specialising in bacteriology, and later virology, in international centres; and where new prophylactic and therapeutic resources - serums and vaccines - could fit into this new approach. Using medical, scientific and legislative sources, a selection from the general press, and archival and printed documentation of the WHO about the social history of medicine and, particularly, the history of the disease, it shows the important role of the training obtained by health professionals in international research centres in the management of both epidemic events, in the modernisation of Spanish science and health before the civil war, and in the post-war reconstruction.

(c) 2021 Asociación Española de Historia Económica

\footnotetext{
* Autor para correspondencia. Correo electrónico: mariaisabel.porras@uclm.es (María Isabel Porras Gallo). 


\section{Introducción}

Desde finales del siglo xix la mortalidad por enfermedades infecciosas constituía un importante problema social en España, pero la esperanza de poder evitarlas se instaló entre la profesión médica con el desarrollo de la bacteriología y, sobre todo, tras la constatación del poder que el suero antidiftérico tenía para tratar la difteria. Los resultados de su uso presentados por Émile Roux en 1894 en el VIII Congreso de Higiene y Demografía generaron nuevas expectativas en el abordaje de las enfermedades infecciosas (Rodríguez-Ocaña, 1994, 2007), y se acarició la idea de que este tipo de patología era evitable. Teóricamente, lo único que se necesitaría sería disponer de sueros y vacunas específicos contra cada enfermedad infecciosa, tras aislar e identificar su germen causal. Proceder así implicaba incorporar el laboratorio en la gestión de los procesos infecciosos y un personal especializado que debía formarse en los primeros centros de investigación y docencia en bacteriología creados: el Instituto Pasteur (París) y el de Robert Koch (Berlín). En este nuevo contexto, las estancias formativas en estos centros, realizadas frecuentemente con becas nacionales e internacionales, eran clave para que los profesionales sanitarios consiguieran ese conocimiento especializado y lo trasladaran posteriormente a sus países de origen para abordar la patología infecciosa. Como veremos, médicos y farmacéuticos especializados en la nueva disciplina en los centros de París, Berlín o Estados Unidos desarrollaron un papel relevante en la lucha contra la gripe de 1918-1919 y las epidemias de poliomielitis en España.

El objetivo de este trabajo es trazar un breve recorrido del impacto de ambos problemas sanitarios y las respuestas dadas para mostrar cómo estos acontecimientos fueron retos, pero también oportunidades para visibilizar el papel que los profesionales sanitarios especializados en bacteriología y luego en virología en centros internacionales podían desempeñar, y el lugar de los recursos profilácticos y terapéuticos -sueros y vacunas- en ese nuevo enfoque. Nos servimos de fuentes médico-científicas, legislativas, una selección de prensa general, documentación de archivo e impresa de la OMS y adoptamos la perspectiva de la historia social de la medicina, y particularmente la de la historia de la enfermedad.

Hasta ahora la historiografía se ha ocupado de la pandemia de gripe de 1918-1919 en España separadamente (Echeverri Dávila, 1993, 2021; Porras Gallo, 2020) o en relación con posteriores episodios pandémicos de la misma enfermedad (Porras Gallo y Ramírez Ortega, 2020), y la presencia epidémica de la polio en nuestro país ha sido objeto de análisis en el marco de tres proyectos coordinados de investigación financiados sucesivos, en los que participó nuestro grupo investigación (Porras Gallo et al., 2013). Sin embargo, hasta ahora no se han examinado conjuntamente ambos sucesos epidémicos para evaluar prioritariamente el papel de las estancias investigadoras de los profesionales sanitarios en la gestión de dichas crisis durante el periodo de modernización científico-sanitaria española antes de la Guerra Civil y de reconstrucción posterior tras el impacto negativo de la contienda.

\section{Contexto y desarrollo la pandemia de 1918-1919}

Desde finales del siglo xIx, parte del colectivo médico relacionó la elevada mortalidad en España, muy superior a casi todos los países europeos y americanos, con nuestra mala situación sanitaria y la inacción de las autoridades gubernamentales, y para reducirla solicitó la aprobación de una nueva ley de sanidad que sustituyera a la de 1855 y se apoyara en la medicina bacteriológica. Tras repetidos intentos sin aprobar más que la Instrucción General de Sanidad de 1904, algunos higienistas cambiaron de estrategia en 1914, también sin éxito (Pulido Fernández, 1914; Porras Gallo, 1994). Optaron por intentar aprobar una ley de epidemias, centrada en la profilaxis pública de las enfermedades infecciosas, para conseguir mejorar la situación sanitaria y la ansiada regeneración del país, dado el valor que la bacteriología y la investigación de laboratorio habían alcanzado internacionalmente en la gestión de la salud de las naciones (Barona Vilar, 2019).

Entre los partidarios de este enfoque destacó el médico militar Manuel Martín Salazar, que formó parte del Instituto de Higiene Militar desde 1898 hasta 1909, lo modernizó e instauró allí una sección para preparar suero antidiftérico y otros sueros y vacunas, tras especializarse en centros investigadores de Alemania y Francia (Barona Vilar, s. f.). Desde 1916 fue inspector general de Sanidad y tuvo gran protagonismo durante la gripe de 1918-1919 por su condición de autoridad sanitaria, pero también como científico y propulsor de medidas legislativas sociosanitarias para evitar otras crisis sanitarias. Para él, la lucha contra las enfermedades infecciosas debía constituir el eje científico-sanitario de la reforma sanitaria por entender estos procesos "evitables» al haber descubierto la ciencia «medios seguros de prevenirlas», los sueros y las vacunas (Porras Gallo, 1994). Además de la necesaria implicación del Estado en materia sanitaria y de investigación científica, una de las dificultades que este médico veía para lograr ese objetivo era disponer de profesionales de la medicina con formación en bacteriología para desempeñar adecuadamente la función de higienista, nueva especialidad que Martín Salazar consideraba debía existir en España, al igual que había en Alemania, Estados Unidos, Inglaterra e Italia (Martín Salazar, 1913, pp. 24-27). La bacteriología no era enseñada separadamente a los médicos en la Universidad en 1913 y no figuró como asignatura independiente en los estudios de Medicina hasta 1928 (García del Carrizo, 1963)'1. Martín Salazar reclamaba corregir esa situación en las facultades de Medicina y, además, instaurar estudios especializados en el Instituto Nacional de Higiene Alfonso XIII para adquirir la especialidad de médico higienista y que esa formación se exigiera para el desempeño de todos los puestos en la Administración sanitaria (Martín Salazar, 1913, pp. 24-27). Este modelo propuesto era básicamente el modelo alemán, que este médico conocía bien por sus estancias en Alemania.

En este contexto, cuando la Primera Guerra Mundial estaba finalizando, comenzó la pandemia de 1918-1919, injustamente conocida como la gripe española, por haber sido silenciados los primeros casos ocurridos en marzo y abril de 1918 en EE.UU., Francia y entre los soldados de la Triple Alianza, y aprovecharse el estallido de la epidemia en Madrid en mayo y la publicidad efectuada de ese episodio para admitir el inicio

\footnotetext{
${ }^{1}$ Desde 1885 se explicaron las bases de la microbiología en algunas de las recién creadas cátedras de Anatomía Patológica, y en 1911 se dotó la primera cátedra de Parasitología y Patología Tropical en la Facultad de Medicina de Madrid (García del Carrizo, 1963; Báguena Cervellera, 1984).
} 
de la crisis sanitaria y atribuir su origen a España (Porras Gallo, 2002, 2020).

La pandemia cursó en tres brotes: primavera de 1918, otoño de 1918 y primavera de 1919, aunque no todos los países registraron los tres. El segundo fue el que mayor número de muertes provocó mundialmente y también en nuestro país. Se calcula que la pandemia de 1918-1919 mató entre 50 y 100 millones de personas en el mundo (Johnson y Müller, 2002), cifra muy superior a las muertes originadas por la Primera Guerra Mundial. En España, la gripe provocó 270000 fallecimientos (Echeverri Dávila, 1993, 2021) y sucedió en un contexto muy crítico. La inestabilidad política dominó el bienio y los Gobiernos se sucedían con rapidez, en medio de una importante crisis social y económica, particularmente grave para la población trabajadora, que soportaba un importante nivel de desempleo, escasez y carestía de los alimentos de primera necesidad y vivía hacinada en viviendas insalubres. A ello se añadió la mala situación sanitaria ya comentada y la insuficiencia de recursos sanitarios materiales y humanos, que tuvieron un negativo efecto al hacer frente a la gripe de 1918-1919. Otro elemento clave que marcó sus respuestas a la crisis sanitaria fue la situación de reorganización profesional en que se encontraban médicos, farmacéuticos y veterinarios, muy influidos por el valor que la medicina bacteriológica había cobrado.

\section{Identificación y origen de la pandemia y establecimien- to de medidas de lucha}

La doctrina bacteriológica impregnó el discurso sobre la gripe en la pandemia de 1889-1890, cuando se buscó su germen específico. La crisis sanitaria finalizó sin conseguirse, pero en 1892 las investigaciones de Richard Pfeiffer le condujeron a proponer al bacilo de Pfeiffer como agente causal de esta enfermedad (Théodorides, 1974). Esta era la doctrina oficial etiológica cuando la pandemia de 1918-1919 comenzó, aunque habían surgido dudas durante algunas epidemias del inicio del siglo $\mathrm{xx}$.

En este contexto científico y tras constatar el comienzo de un proceso epidémico en Madrid en mayo de 1918, la profesión médica estableció que desde un punto de vista clínico la gripe era la responsable de esa crisis sanitaria, aunque al ser una enfermedad infecciosa algunos médicos consideraron imprescindible confirmar el diagnóstico en el laboratorio y se desarrollaron investigaciones para aislar el bacilo de Pfeiffer en los productos y secreciones de las personas enfermas (Porras Gallo, 2002, p. 297). Esta labor se desplegó en laboratorios municipales, provinciales y en el Instituto Nacional de Higiene Alfonso XIII, pero también en algunos hospitales de la sanidad civil y militar y cátedras universitarias de Higiene. Tuvieron mayor protagonismo los ubicados en Madrid (Laboratorio Municipal, Hospital Militar e Instituto de Higiene Militar), Barcelona (Instituto Municipal de Higiene), Valencia (Laboratorio Municipal de Bacteriología e Instituto Provincial de Higiene y Laboratorio de Sanidad Militar) y Sevilla (Cátedra de Higiene de la Universidad). Su actuación estuvo marcada por encontrarse al frente de estas instituciones profesionales sanitarios con formación especializada en bacteriología, que habían adquirido en los principales centros investigadores europeos (Porras y Báguena, 2020a).

Ahora bien, los resultados de estas investigaciones cuestionaron nuevamente el papel del bacilo de Pfeiffer como agente de la gripe. Su aislamiento no se producía en todos los casos de enfermedad; se aislaban otros gérmenes solos o combinados y no era posible establecer que uno de esos microbios estaba presente en todas las muestras patológicas de las personas enfermas. Junto al bacilo de Pfeiffer, que algunos seguían postulando como agente de la gripe, se propusieron otros microbios como causantes de esta enfermedad. Estreptococos, neumococos, meningococos, una asociación bacteriana, un germen desconocido o un "virus filtrable» fueron las propuestas etiológicas formuladas, generándose un importante debate en revistas científico-profesionales, en las sesiones de la Real Academia Nacional de Medicina y en la prensa de información general (Porras Gallo, 2002). Conviene destacar que la hipótesis del "virus filtrable» fue realizada por especialistas en bacteriología, como el médico Martín Salazar y los veterinarios Dalmacio García Izcara y Ramón Turró (Porras Gallo, 2002, 2020).

En ninguno de los tres brotes el laboratorio pudo demostrar que alguno de esos microbios cumplía los postulados de Robert Koch, y tampoco hubo acuerdo entre los profesionales sanitarios para considerar agente específico de la gripe a alguno de ellos (Porras Gallo, 2008, 2020). Esta situación revelaba las limitaciones de la medicina bacteriológica para fijar la etiología de la gripe e impedía disponer de recursos profilácticos y terapéuticos específicos para contener la epidemia, tratar las personas enfermas y reducir la mortalidad. Era un revés para las expectativas de los médicos defensores de la bacteriología y colocaba a este colectivo en una posición complicada, que trascendió a la sociedad a través de la prensa de información general. En sus páginas se mostró cierta desconfianza y se efectuaron críticas $(A B C, 28-5-1918$, p. 10) que médicos y farmacéuticos combatieron mediante la difusión de sus trabajos (El Sol, 24-5-1918; El Sol, 11-6-1918, p. 8).

Pese a la imposibilidad de fijar cuál era el microbio de la gripe, los médicos propusieron y utilizaron recursos profilácticos y terapéuticos empleados tradicionalmente contra otras epidemias y los nuevos instrumentos de la medicina bacteriológica, dada la gravedad de la crisis sanitaria, la necesidad de actuar y de mantener su condición de expertos. Entre los medicamentos tradicionales figuraron purgantes, tónicos, sudoríficos, excitantes, antipiréticos, desinfectantes, baños, dieta sana, aireación y sangrías (Porras Gallo, 2002, pp. 346-352). Aunque con notas comunes, cada facultativo optó por un tratamiento. Coincidiendo con el segundo brote pandémico y la escasez y carestía de medicamentos, la Inspección General de Sanidad solicitó a la Real Academia de Medicina el listado de medicamentos indispensables para tratar la gripe para facilitar su disponibilidad y acceso. Como desinfectantes, la Academia consideró hipocloritos, formol, azufre, derivados de la hulla, creolina y cresol, y como tratamiento los sueros más opio y derivados, sales de quinina, digital y derivados, yodo, yoduros, antipirina, aspirina, piramidón, entorina, acetato y carbonato amónicos, esparteína y sus sales, estricnina y sus sales, cafeína y sus sales, colesterina, adrenalina, salicilato sódico, alcanfor, novocaína y benzoato sódico ${ }^{2}$. La decisión sobre los sueros

\footnotetext{
2 Archivo de la Real Academia Nacional de Medicina. Carpeta 289 (Papeles diversos. Años 1918-1919). "Carta fechada el 29 de octubre de 1918 y dirigida a la Real Academia Nacional de Medicina por la Inspección General de Sanidad, Ministerio de la Gobernación», en la que se pregunta sobre "los medicamentos más indispensables en el tratamiento de la gripe, con el fin de poner remedio a la escasez de ellos en el mercado y evitar el acaparamiento y el exceso de precio de los mismos», y «Respuesta que dio la Academia a la cuestión».
} 
generó un gran debate en la Academia, centrado en el suero antidiftérico y los sueros antiestreptocócicos y antineumocócicos, ante las dudas sobre el germen de la gripe. Los profesionales sanitarios más comprometidos con el enfoque bacteriológico y con especialización foránea, como Gustavo Pittaluga, Antonio Ruiz Falcó y Gregorio Marañón, fueron contrarios a considerar el suero antidiftérico como tratamiento contra la gripe, por falta de especificidad. Algunos de sus defensores lo justificaban para calmar el ánimo de la población. Por el contrario, los nuevos sueros se consideraron tratamientos útiles contra las complicaciones de la gripe, pero no contra ella (Porras Gallo, 2008, 2020).

Para la profilaxis se combinaron medidas de higiene pública, aplicadas tradicionalmente contra las crisis epidémicas, con el empleo de distintas vacunas (contra varios gérmenes o contra neumococos) que estuvieron preparadas al final del segundo brote por profesionales sanitarios con formación internacional en bacteriología, como el farmacéutico César Chicote y los médicos Jaime Ferrán, Juan Peset, Pablo Colvée y Adolfo Rincón de Arellano, y con validez solo para complicaciones de la gripe (Porras Gallo, 2008). Además de extremar la limpieza de la vía pública, los mercados y mataderos, el uso de desinfecciones de mercancías y pasajeros en estaciones fronterizas, de tren y tranvías, se pidió evitar las aglomeraciones, los espacios cerrados y mal ventilados, se recomendó el aislamiento de enfermos y durante el segundo brote se cerraron los centros docentes públicos, aunque no los privados ni cines, teatros y otros espacios de ocio. Este hecho motivó importantes críticas por la sociedad. Desde la medicina se sentían indefensos por la falta de especificidad de los recursos profilácticos, como Martín Salazar confesó, pero algunos las defendían para tranquilizar a la población (Porras Gallo, 2002). La pandemia de COVID-19 y algunos estudios sobre la gripe de 1918-1919 han mostrado la utilidad de estas medidas si se aplican en debida forma y con los productos apropiados (Porras Gallo, 2020).

\section{Factores que explicaban la gravedad de la pandemia, propuestas médicas para corregirlos y respuestas del Gobierno y poderes públicos}

Junto a las dificultades científicas expuestas, parte de la profesión médica explicó la gravedad de la pandemia por el retraso del Gobierno en tomar medidas y su insuficiencia y, sobre todo, por los condicionantes socioeconómicos y nuestras deficiencias científico-sanitarias organizativas, legislativas y escasez de infraestructuras y recursos humanos especializados en bacteriología. Este último grupo eran antiguas demandas de la clase médica que cobraron nueva relevancia por la pandemia. Este planteamiento causal holístico de la pandemia, realizado fundamentalmente durante el segundo brote, cuando la mortalidad era superior, otorgó un papel también a la insalubridad de viviendas, el hacinamiento, la escasez y carestía de alimentos y productos de primera necesidad y las malas condiciones de trabajo (Porras Gallo 1994, 2020). Recientemente, Svenn-Erik Mamelund ha corroborado el impacto demográfico negativo de estos factores para Noruega (Mamelund, 2006, 2017).

En consonancia con esta visión, se propusieron actuaciones particulares sobre algunos factores señalados y se presentaron entre julio de 1919 y mayo de 1922 sucesivos proyectos de ley de profilaxis pública de enfermedades infecciosas, que incluían medidas de prevención adaptadas a la medicina bacteriológica, otras de índole ambiental y de previsión social, como la instauración de los seguros sociales o únicamente los seguros obligatorios de enfermedad y maternidad con medidas de higiene industrial, escolar y del trabajo. La autoría y protagonismo de estas iniciativas legislativas correspondió a médicos, como Manuel Martín Salazar, Amalio Gimeno y otros, con formación especializada en bacteriología adquirida fuera de nuestras fronteras y partidarios de la higiene social. Al igual que ocurrió antes de la pandemia de gripe, estas iniciativas legislativas fueron desestimadas (Porras Gallo 1994, 2020). El Gobierno aprobó solo el limitado real decreto de prevención de enfermedades contagiosas de enero de 1919 y algunas acciones concretas demandadas para corregir algunos déficits científico-sanitarios existentes, a las que la crisis sanitaria otorgó mayor visibilidad. Entre ellas, de interés para este artículo, y antes del fin de la pandemia, fueron la obligatoriedad de laboratorios municipales para efectuar análisis bacteriológicos y desinfecciones, la adquisición de los terrenos para construir el Hospital de Epidemias en Madrid en diciembre de 1918 y el reglamento de elaboración de sueros y vacunas en 1919 y la creación de las brigadas provinciales en 1921.

Las acciones de los poderes públicos municipales, provinciales y estatal en la compleja coyuntura de la gripe de 19181919 se emprendieron generalmente con retraso, tras haber negado la existencia de la crisis sanitaria y siguieron un patrón similar, que buscó mantener la tranquilidad de la población, reforzar la asistencia sanitaria y social, mejorar las condiciones higiénicas, facilitar el acceso a alimentos, recursos de primera necesidad y medicamentos para combatir la gripe, junto a las acciones profilácticas recomendadas por los profesionales sanitarios. Todo ello entrañó costes importantes para los que articularon créditos especiales municipales, provinciales y estatales, que fueron insuficientes (Porras Gallo, 2002, 2020; León, 2014).

Aunque el interés que la experiencia de la gripe de 1918-1919 suscitó por subsanar las deficiencias sociosanitarias se mantuvo vivo tras su finalización, la materialización de las medidas aprobadas durante la crisis sanitaria se demoró hasta mediados de la década de los veinte o treinta. Fueron precisos nuevos contextos político-económicos y la colaboración de la Fundación Rockefeller (FR). Esta se logró mediante acuerdo firmado en 1922, que entró en vigor en 1924 en plena Dictadura de Primo de Rivera. Una de las cuestiones clave de la lentitud de ejecución, como señaló el informe de Charles Bayle, experto que la FR envió a España desde diciembre de 1924 hasta abril de 1926, no fue únicamente falta de recursos, sino principalmente falta de decisión política y la escasa prioridad otorgada a la salud. Su estancia le permitió advertir cómo, a veces, se contaba con instalaciones sanitarias con equipamiento caro sin utilizar por falta de personal especializado, mientras que en otras ocasiones el personal sanitario no podía desarrollar sus funciones por carecer de instalaciones adecuadas (Barona Vilar y Bernabeu-Mestre, 2008; Rodríguez-Ocaña, 2001a, 2019).

Una de las realizaciones ligadas al acuerdo con la FR fue crear la Escuela Nacional de Sanidad (Madrid), inspirada en la School of Hygiene and Public Health de la Universidad Johns Hopkins, con el objetivo de proporcionar formación especializada en Salud Pública para los médicos de la Administración sanitaria (Bernabeu-Mestre, 1994, 2009-2010; Barona Vilar y Bernabeu-Mestre, 2008), que Martín Salazar había reclamado en 1913 (Martín Salazar, 1913). No comenzó su actividad hasta 1925, cuando se inauguró también el Hospital de Enfermeda- 
des Infecciosas u Hospital del Rey, demandado por los médicos durante la gripe de 1918-1919, cuando únicamente se adquirieron los terrenos. Estas dos iniciativas, junto al Reglamento de Sanidad Provincial, promulgado igualmente en 1925 y que creaba los institutos provinciales de Higiene, representaron el paso de nuestra salud pública a su etapa de consolidación, que se extendió hasta 1957 (Rodríguez-Ocaña, 2001a, 2001b). La publicación del informe de Bayle impulsó nuevas transformaciones en 1927, como el desarrollo real de los institutos provinciales de Higiene y de su función de control de las enfermedades infecciosas a través de financiación mancomunada por los ayuntamientos. Otra, ejecutada con el apoyo económico de la FR, fue la fundación del Servicio Epidemiológico Central. Estas transformaciones contribuyeron, aunque con limitaciones, a la modernización sanitaria (Barona Vilar, 2015; Rodríguez-Ocaña, 2000; Weindling 1993, 1995) y a afrontar en 1929 la primera epidemia de mayor entidad de poliomielitis, nuevo problema sociosanitario al que España se enfrentó fundamentalmente tras la Guerra Civil (Porras Gallo et al., 2013). Un elemento crucial en esa modernización sanitaria y en las actuaciones contra la poliomielitis fue la especialización que alcanzaron algunos profesionales sanitarios entre 1925 y 1936 mediante estancias realizadas en los principales laboratorios y centros de investigación extranjeros con ayuda de becas de la FR, como Bayle recomendó en su informe.

De modo paralelo y lento se mantuvo el empuje de la pandemia de 1918-1919 en la investigación bacteriológica y luego en la virológica, que se benefició también de becas de la FR y permitió responder con limitaciones a los nuevos retos virológicos, como el de la poliomielitis, durante el periodo franquista (Porras y Báguena, 2020a, 2020b).

\section{La poliomielitis como problema social. Nuevo reto y nuevas oportunidades}

A finales del siglo xIx y principios del xx, con posterioridad a los países escandinavos, Canadá y EE.UU., la poliomielitis provocó brotes epidémicos esporádicos en España, que alcanzaron mayor regularidad tras la epidemia registrada en Madrid en 1929, a la que sucedieron otras en 1930 (Santander) y 1932 (Mallorca) (Hauser, 1913; Sales Vázquez, 1955, p. 254; De las Heras et al., 2013, p. 48). Algunas de las mejoras sanitarias posibilitaron una gestión más moderna de la epidemia de 1929, cuando tuvieron gran protagonismo el Servicio Epidemiológico Central en la detección y estudio del brote ${ }^{3}$, y el Hospital del Rey en la atención sanitaria (Porras Gallo y Báguena Cervellera, 2013).

El primero, dirigido por Laureano Albaladejo, estudió la epidemia que provocó 318 casos, la mayoría localizados en la ciudad de Madrid (187) y el resto repartidos entre municipios de su provincia (59) y de las de Toledo, Ávila y Cáceres (Albaladejo García-Berenguer, 1930). Tras los primeros casos de polio de junio, julio y agosto de 1929 en Madrid, se declaró el estado oficial de epidemia y se adoptaron medidas, como la búsqueda de casos en centros sanitarios de la ciudad (hospitales, laboratorios y consultorios) y el recordatorio a los médicos de la obligatoriedad de declarar los casos de polio diagnos-

\footnotetext{
${ }^{3}$ Este servicio, heredero de la Brigada Sanitaria Central (1920), impulsó el uso de la estadística en la epidemiología (Marset, Rodríguez Ocaña y Sáez, 1998; Rodríguez Ocaña, 2001a).
}

ticados. Se coordinaron y distribuyeron las tareas entre los profesionales sanitarios para efectuar adecuadamente el estudio epidemiológico del brote epidémico. Se habilitó el Laboratorio del Servicio Epidemiológico Central (id.). Es importante destacar que el médico Laureano Albaladejo poseía buena formación especializada, obtenida en centros internacionales relevantes con ayuda de una beca de la FR (Ballester y Porras, 2009), que facilitó que realizara el primer informe sobre un brote de poliomielitis en España conforme a la epidemiología moderna, con un excelente estudio descriptivo que incluyó también investigación experimental y el método estadístico en el análisis epidemiológico (Martínez Navarro et al., 2004). Colaboraron en la realización seis enfermeras visitadoras de Cruz Roja, que confeccionaron fichas epidemiológicas que seguían los estándares internacionales de países europeos de nuestro entorno (Alemania, Francia y Gran Bretaña). Desde una visión multicausal, se evaluó el papel de todos los factores responsables de poder causar y difundir la epidemia de poliomielitis, como el saneamiento y estado de las viviendas de cada barrio de Madrid, sus características demográficas, la leche y las moscas (Albaladejo García-Berenguer, 1930).

Por su parte, el Hospital del Rey, dirigido por Manuel Tapia, médico que también se benefició del programa de becas de la FR para ampliar su formación en patología infecciosa ${ }^{4}$, permitió un abordaje asistencial de la poliomielitis conforme a las recomendaciones del Comité Permanente de la Oficina Internacional de Higiene Pública (Fernández Ruiz-Sánchez, 1930, p. 777), consistentes en el uso del hospital para tratar la poliomielitis aguda y sus secuelas crónicas, y en el empleo de la seroterapia (Tapia Martínez, 1930a, 1930b). Este último tratamiento exigió disponer de cantidad suficiente de suero de convalecientes para administrárselo a los 112 pacientes ingresados en el Hospital del Rey, y fue preciso recurrir a niños ingresados en el Asilo-Hospital de San Rafael (Madrid). El suero se administró como único tratamiento o asociado a electroterapia, diatermia y radioterapia profunda, conforme al método Bordieu (id.).

El desarrollo de la Guerra Civil y sus consecuencias tuvo un impacto negativo en términos epidemiológicos, con la aparición de nuevas epidemias de poliomielitis, sobre todo a su finalización, pero también influyó en el empeoramiento del nivel científico-sanitario asistencial e investigador alcanzado antes de la contienda. No fue únicamente por falta de infraestructuras -el edificio del Instituto Nacional de Higiene Alfonso XIII quedó destruido y no se reconstruyó-, sino también por el exilio o la represalia de los científicos y sanitarios más relevantes (Barona Vilar y Bernabeu-Mestre, 2008). Este nuevo escenario dificultó la lucha contra las epidemias de poliomielitis en la etapa franquista (Porras Gallo et al., 2013; Porras y Báguena, 2020a, 2020b).

\section{El drama de la poliomielitis en la España franquista}

La tendencia alcista de la morbimortalidad por poliomielitis continuó finalizada la Guerra Civil, con mayor gravedad desde 1950 hasta 1963, cuando se efectuó la primera campaña masiva de vacunación. Aunque el régimen franquista no reconoció

\footnotetext{
${ }^{4}$ Realizó estancias en los Institutos Serológicos de Copenhague, Frankfurt, el Instituto Rockefeller y los Hospitales de Enfermedades infecciosas de Boston y Nueva York (Porras Gallo, s.f.).
} 
su existencia hasta 1958, adoptó algunas medidas no materializadas, como la Orden del 4 de agosto de 1947 (BOE, 14-81947), que establecía la creación de cuatro centros contra la poliomielitis a ubicar en Madrid, Barcelona, Santander y Sevilla (De las Heras et al., 2013, p. 58). Esta medida fue una tímida respuesta a peticiones de algunos médicos que, al igual que antes de la contienda, estuvieron al tanto de las ideas internacionales sobre el abordaje de las fases aguda y crónica de la poliomielitis (Porras Gallo y Báguena Cervellera, 2013, pp. 105-106). De hecho, en 1947 el neurólogo y neurocirujano José María Izquierdo, que había completado su especialización en Zúrich y París (Martínez Rodríguez, s. f.) y conocía la experiencia de los EE.UU. con la poliomielitis, presentó un plan de atención integral que incluía, entre otras cosas, la necesidad de establecer hospitales y centros especializados para esta patología, pero también de crear una estructura nacional administrativa para centralizar las iniciativas terapéuticas (Izquierdo Rubín, 1947).

El contenido de la Orden de 1947 se reactivó en 1951 (Decreto de 23 de marzo de 1951, BOE, 25-4-1951, 115, p. 1879), tras triplicarse la tasa de morbilidad en 1950. En él se disponía la instauración del Servicio Antipoliomielítico en el Hospital del Niño Jesús (Madrid), que no ocurrió hasta 1959, coincidiendo con la mayor tasa de morbilidad alcanzada. Esta enorme gravedad otorgó nuevo protagonismo al Hospital del Rey, ya no dirigido por Manuel Tapia por haber sido represaliado por el régimen franquista, sino por Juan Torres Gost. Este último médico, cuando se decidió en 1955 que se crearía un Servicio Nacional Antipoliomielítico en el Hospital del Rey, viajó por hospitales europeos y servicios hospitalarios de poliomielitis (París, Munich, Inglaterra y países escandinavos) para recabar información para construirlo. Hasta 1958, cuando se celebró el V Simposio de la Asociación Europea contra la Poliomielitis en Madrid, no se creó dicho servicio, aunque se inauguró en 1960, tras registrarse la mayor morbilidad por poliomielitis en España (Porras Gallo y Báguena Cervellera, 2013, p. 107). Paralelamente, se articularon centros en otras localidades, se adaptaron sanatorios antituberculosos y se usaron centros privados religiosos, también insuficientes para el volumen de casos.

Junto a estas acciones, y a diferencia de la epidemia de 1929, se pudo contar con la vacuna inyectable de Jonas Salk desde 1955, y desde 1961 con la vacuna oral de Albert Sabin. Estos nuevos recursos cambiaron la gestión de la presencia epidémica de la poliomielitis, ya que al poder evitar nuevas víctimas de esta enfermedad también se impedía que sufrieran secuelas el resto de su vida.

Sin embargo, en España el uso de la primera de estas vacunas se retrasó hasta 1958 y se aplicó escasamente. De ahí el incremento de morbilidad hasta finales de 1963, cuando se aplicó masivamente la primera dosis de la vacuna oral de Sabin, y en la primavera de 1964 la segunda dosis a todos los menores de siete años. Esta acción, las sucesivas campañas anuales de vacunación a los recién nacidos y de revacunación posterior y el establecimiento en 1975 del primer calendario nacional de vacunación infantil permitieron que disminuyera la morbilidad por poliomielitis más lentamente que en la mayoría de los países europeos de nuestro entorno hasta 1988, cuando se registró el último caso (Porras Gallo et al., 2013).

Son numerosas las razones que permiten explicar el retraso en el inicio de la vacunación, justificada por el director general de Sanidad, José Alberto Palanca, por la escasa presencia de la enfermedad en España - algo que los datos de morbilidad desmentían- y para esperar a que se comprobara la eficacia de la vacuna Salk tras el incidente Cutter $^{5}$ (La Gaceta, 26-61951, p. 1). Tras esas palabras se escondían insuficiencias en infraestructuras científico-sanitarias y falta de personal especializado, que impedían la realización de una encuesta serológica previa para decidir la estrategia de inmunización, el seguimiento de las personas inmunizadas, una producción propia de vacuna contra la polio y provocaban una dependencia del exterior para adquirirla, con el consabido gasto de divisas; pero también hay que citar las luchas entre las distintas facciones políticas que soportaban el régimen franquista y la negativa a reconocer la poliomielitis como problema de salud, pese a que España estaba solicitando ayuda técnica colaborativa a la OMS desde 1952 para hacer frente a los distintos déficits y poder lucha contra los principales problemas infecciosos (Porras y Báguena, 2020a).

Aunque nuestro país, a diferencia de Suecia y Francia, nunca tuvo vacuna propia contra la poliomielitis ni produjo las de Salk o Sabin, el apoyo de los programas país de la OMS, sus programas de becas para mejorar la especialización de científicos y profesionales sanitarios y el empuje ante el Gobierno franquista para mejorar las infraestructuras científico-sanitarias existentes y crear otras nuevas, fue crucial para efectuar transformaciones científico-sanitarias y posibilitar la realización de una encuesta serológica, que determinó que era preciso vacunar a los menores de siete años, y para vencer las resistencias frente a la vacuna oral de Sabin del régimen franquista y de parte de los profesionales sanitarios y seleccionarla para su administración masiva (Porras et al., 2013). Figura clave en este proceso fue Florencio Pérez Gallardo, privilegiado por el régimen franquista frente al virólogo Eduardo Gallardo -que contaba con experiencia en investigación y producción de vacunas en el Instituto de Higiene Alfonso XIII y como profesor de Enfermedades Víricas en la Escuela Nacional de Sanidad (ENS), pero no con la confianza del régimen (Porras y Báguena, 2020a)-, y su grupo en el Laboratorio de Virus de la Escuela Nacional de Sanidad 6 .

Pérez Gallardo gozó del apoyo de Gerardo Clavero, director de la ENS desde 1941 y uno de sus antiguos profesores en la Facultad de Medicina de Cádiz como catedrático de Higiene, que se lo llevó con él a la ENS y le introdujo en la virología y las vacunas (Rodríguez-Ocaña, 2017). Gracias a distintas becas, financiadas por el Gobierno español, la Junta de Relaciones Culturales del Ministerio de Asuntos Exteriores (programa heredero del de la JAE) y la OMS, obtuvo una formación especializada en centros investigadores de Berlín, Lisboa, Marruecos y Nueva York (laboratorios de la FR) (Porras y Báguena, 2020a), en el Instituto Estatal Serológico (Copenhague) y otros de Francia, Italia, Suecia, Dinamarca y Suiza (Ballester, 2016). Este bagaje científico, el apoyo del Gobierno español, los contactos establecidos con miembros de la OMS y los programas

\footnotetext{
${ }^{5}$ Este incidente alude a la aparición de casos de poliomielitis en EE.UU. en 1955, poco después de comenzar la inmunización masiva de su población infantil, que se relacionó con un fallo en un lote de la vacuna del laboratorio Cutter (Offit, 2005).

${ }^{6}$ Eduardo Gallardo, formado en el Instituto Pasteur (París) y el Instituto Rockefeller de Investigación Médica (New York), gracias a una beca de la FR y buenas relaciones con dichos grupos (Rodríguez Ocaña, 2014), desarrolló una neurovacuna contra la viruela en 1923 (Gallardo, 1924). La FR concedió financiación a Gallardo para su laboratorio de investigación en Madrid (Báguena Cervellera, 2015; Porras y Báguena, 2020a).
} 
colaborativos de esa agencia internacional constituyeron un buen soporte para sus actividades como jefe del Servicio del Virus de la ENS y, desde 1968, al frente de la nueva institución, el Centro Nacional de Virología y Ecología Sanitaria de Majadahonda que, entre otras cosas, posibilitaron la ejecución de la primera encuesta serológica sobre la situación epidemiológica de la poliomielitis en España, realizada en su laboratorio de la ENS con una ayuda de la Fundación Juan March (Ballester y Porras, 2009), la primera campaña masiva de vacunación en 1963 y su seguimiento posterior. Aunque Florencio Pérez Gallardo elaboró vacunas contra la polio del tipo Salk y Sabin con fines investigadores, tuvo que renunciar a una producción propia, como estaba haciendo Pierre Lépine en el Instituto Pasteur, por falta de apoyo del Gobierno franquista y la gran dependencia de ayuda de la OMS (Porras y Báguena, 2020a). Las campañas de vacunación debieron hacerse siempre con vacunas de laboratorios privados, al igual que las inmunizaciones tras instaurarse el primer calendario nacional de vacunación infantil.

\section{A modo de reflexión final}

La introducción de la bacteriología, de los sueros y las vacunas en la medicina modificó el abordaje de las enfermedades infecciosas y de las crisis sanitarias por dicha causa y dotó a los centros de investigación bacteriológica y virológica de un nuevo valor como proveedores de ese conocimiento especializado que los profesionales sanitarios precisaban. La pandemia de gripe de 1918-1919, las epidemias de poliomielitis de 1929 y las de la etapa franquista fueron un reto para la sociedad, visibilizaron los problemas existentes, pero también constituyeron oportunidades para solicitar e introducir mejoras para corregir o mitigar algunas de las deficiencias. Para hacerlo y gestionar estas crisis sanitarias una pieza clave fue la formación especializada conseguida por los profesionales sanitarios españoles en centros internacionales sanitarios investigadores, que contribuyó a la modernización científico-sanitaria antes de la Guerra Civil y a la reconstrucción posterior tras el negativo impacto de la contienda.

\section{Agradecimientos}

Investigación realizada en el marco de los proyectos financiados por la JCCM-FEDER (ref. SBPLY/17/180501/000382) y MINECO-FEDER (ref. PID2019-108813GB-I00).

\section{Bibliografía}

Albaladejo García-Berenguer, L. (1930). «Estudio de la epidemia de poliomielitis infantil presentada en Madrid durante los cuatro últimos meses de 1929 en Servicio Epidemiológico Central», en Primera memoria anual de los trabajos llevados a cabo por el Servicio Central. Año 1929. Madrid: Ministerio de la Gobernación, pp.106-159.

Báguena Cervellera, M. J. (1984). «La microbiología en el siglo xIx español: organización de su actividad científica», Medicina Española, 83, 180-183.

Báguena Cervellera, M. J. (2015). «La producción y difusión de las vacunas en España: la vacuna antivariólica,» en Barona Vilar, J. L. y Guillem, X. (eds.). Sanidad internacional y transferencia del conocimiento. Europa, 1900-1975. Valencia: PUV, pp. 85-106.

Ballester, R. (2016). España y la Organización Mundial de la Salud en el contexto de la historia de la salud pública internacional (1948-1975). Valencia: Real Academia de Medicina de la Comunidad Valenciana.
Ballester, R. y Porras, M. I. (2009). «El significado histórico de las encuestas de seroprevalencia como tecnología de laboratorio aplicada a las campañas de inmunización El caso de la poliomielitis en España», Asclepio 61 (1), 55-80.

Barona Vilar, J. L. (2015). The Rockefeller Foundation, Public Health and International Diplomacy, 1920-1945. London; New York: Routledge.

Barona Vilar, J. L. (2019). Health policies in Interwar Europe. A transnational perspective. London; New York: Routledge.

Barona Vilar, J. L. y Bernabeu-Mestre, J. (2008). «La Fundación Rockefeller y la salud pública en España», en La Salud y El Estado: el movimiento sanitario internacional y la administración española (1851-1945). Valencia: PUV, pp. 89-142.

Barona Vilar, J. L. (s. f.). "Manuel Martín Salazar», en Diccionario Biográfico Electrónico, Real Academia de la Historia. Madrid. Disponible en: http://dbe.rah. es/biografias/24662/manuel-martin-salazar

Bernabeu-Mestre, J. (1994). «El papel de la Escuela Nacional de Sanidad en el desarrollo de la Salud Pública en España,1924-1934», Revista de Sanidad e Higiene Pública, 68, 65-89.

Bernabeu-Mestre, J. (2009-2010). "La Escuela Nacional de Sanidad», Eidos. Revista de la Fundación Ciencias de la Salud, 32, 74-80.

De las Heras Salord, J., Porras Gallo, M. I. y Báguena Cervellera, M. J. (2013). «La emergencia de la poliomielitis como problema social en Madrid, Valencia y Castilla-La Mancha", en Porras Gallo, M. I. et al. (coords.). El drama de la polio. Un problema social y familiar en la España franquista. Madrid: Los libros de la Catarata, pp. 73-93.

Echeverri Dávila, B. (1993). La gripe española: la pandemia de 1918-1919. Madrid: Centro de Investigaciones Sociológicas.

Echeverri Dávila, B. (2021). La gripe española cien años después: la historia de la pandemia en España y en el mundo. Breve crónica del COVID-19 (Versión Kindle).

Fernández Ruiz-Sánchez, L. (1930). Comité Permanente de la Oficina Internacional de Higiene Pública. Boletín Técnico de la Dirección General de Sanidad, 767-780.

Gallardo, E. (1924). Valor práctico de la neurovacuna. Archivos del Instituto Nacional de Higiene Alfonso XIII, 3 (3), 112-124.

García del Carrizo, G. (1963). Historia de la Facultad de Medicina de Madrid, 18431931 [tesis doctoral]. Universidad Complutense de Madrid.

Hauser, Ph. (1913). Geografía de la Península Ibérica. Madrid: Imprenta Eduardo Arias.

Johnson, N. y Müller, J. (2002). «Updating the accounts: Global Mortality of the 1918-1920 Spanish Influenza Pandemic», Bulletin of the History of Medicine 76, 105-115.

León Sáez, P. (2014). «A collaborative experience: The Mutual Benefit Societies Response to the 1918-19 Influenza Pandemic in Pamplona (Spain), en Porras Gallo, M. I. y Davis, R. A. (eds.). The Spanish Influenza Pandemic of 1918-1919. Perspectives from the Iberian Peninsula and the Americas. Rochester: University of Rochester Press, pp. 152-170.

Mamelund, S. E. (2006). "A socially neutral disease? Individua social class, household wealth and mortality from Spanish Influenza in two socially contrasting parishes in Kristiania, 1918-1919», Social Sciences and Medicine, 62, 923940.

Mamelund, S. E. (2017). "Social inequality. A forgotten factor in pandemic influenza preparednes», Tidsskr Nor Laegeforen, 137 (12-13), 911-913.

Marset Campos, P., Rodríguez-Ocaña, E. y Sáez Gómez, J. M. (1998). «La salud Pública en España», en Martínez Navarro, F. et al. Salud pública. Madrid: Mac Graw Gill Interamericana, pp. 25-47.

Martín Salazar, M. (1913). La sanidad en España. Discurso de ingreso en la Real Academia Nacional de Medicina. Madrid: Real Academia Nacional de Medicina.

Martínez Navarro, F., Paéz, A. y Larrosa Montañés, P. (2004). "Estudio de la epidemia de poliomielitis infantil presentada en Madrid durante el año 1929 por el Dr. Laureano Albadalejo. Primera memoria anual de los trabajos llevados a cabo por el Servicio Epidemiológico Central (1929)», en Martínez Pérez, J. et al. (coord.). La medicina ante un nuevo milenio. Una perspectiva histórica. Cuenca: Universidad de Castilla-La Mancha, pp. 963-987.

Martínez Rodríguez, E. (s. f.). "José María Izquierdo Rubín», en Diccionario Biográfico Electrónico, Real Academia de la historia, Madrid. Disponible en: http:// dbe.rah.es/biografias/76307/jose-maria-izquierdo-rubin

Offit, P. (2005). The Cutter incident. How America»s first polio vaccine led to the growing vaccine crisis. New Haven-London: Yale University Press.

Porras Gallo, M. I. (1994). «La lucha contra las enfermedades evitables en España y la pandemia de gripe de 1918-1919», Dynamis, 14, 159-183.

Porras Gallo, M. I. (2002). Una ciudad en crisis: la epidemia de gripe de 1918-19 en Madrid. Madrid: Servicio de publicaciones de la Universidad Complutense de Madrid [CD ROM].

Porras Gallo, M. I. (2008). «Sueros y vacunas en la lucha contra la pandemia de gripe de 1918-1919», Asclepio, 60 (2), 261-288. 
Porras Gallo, M. I. (2020). La gripe española 1918-1919. Madrid: Los Libros de la Catarata.

Porras Gallo, M.I. (s. f.). «Manuel Tapia Martínez», en Diccionario Biográfico Electrónico, Real Academia de la historia. Madrid. Disponible en: http://dbe.rah.es/biografias/18159/manuel-tapia-martinez

Porras Gallo, M. I. et al. (coords.). (2013). El drama de la polio. Un problema social y familiar en la España franquista. Madrid: Los libros de la Catarata.

Porras Gallo, M. I. y Báguena Cervellera, M. J. (2013). «La respuesta institucional y científica frente a la enfermedad a través de los casos de Madrid, Valencia y Castilla-La Mancha. Atención sanitaria a la polio y sus secuelas y reintegración social de las víctimas», en Porras Gallo, M. I. et al.(coords.). El drama de la polio. Un problema social y familiar en la España franquista. Madrid: Los libros de la Catarata.

Porras, M. I. y Báguena, M. J. (2020a). «The role of the World Health Organization country programs in the development of virology in Spain, 1951-1975", História, Ciências, Saúde-Manguinhos, 27 (supl.), 187-210.

Porras, M. I. y Báguena, M. J. (2020b). «El papel desempeñado por los médicos, el gobierno y la OMS en la implementación de las encuestas serológicas sobre polio, sarampión y rubeola en España (1958-1978)», Asclepio, 72 (1), 294.

Porras Gallo, M. I. y Ramírez Ortega, M. (2020). «Los efectos de la pandemia de 1918-1919 en la lucha contra la gripe en España: el papel de los cambios de percepción del riesgo y la posterior creación de la OMS», en Ferreira, A. (coord.). A Gripe Espanhola de 1918. Guimaraes: Casa Sarmento-Centro de Estudios do Patrimonio, Universidad do Minho, pp. 13-34.

Pulido Fernández, A. (1914). «La ley sobre epidemias y la asamblea de titulares», Siglo Médico, 3180, 739-740.

Rodríguez-Ocaña, E. (1994). «El tratamiento de la difteria en la España de la segunda mitad del siglo xIX», Medicina e Historia, 54, 5-28.

Rodríguez-Ocaña, E. (2000). «La intervención de la Fundación Rockefeller en la creación de la sanidad contemporánea en España», Revista Española de Salud Pública, 74, 27-34.

Rodríguez-Ocaña, E. (2001a). «The politics of Public Health in the Siate-Managed Scheme of Healthcare in Spain (1840-1990)», en Lowy, I. y Krige, J. (eds.). Images of Disease, Science, Public policy and Health in Postwar Europe. Luxem- bourg: Office for Official Publications of the European Communities, pp.187210.

Rodríguez-Ocaña, E. (2001b). «La salud pública en la primera mitad del siglo xx», en Atenza, J. y Martínez Pérez, J. El Centro Secundario de Higiene Rural de Talavera de la Reina y la sanidad española de su tiempo. Cuenca: Junta de Comunidades de Castilla La Mancha, pp. 21-42.

Rodríguez-Ocaña, E. (2007). «La producción social de la novedad: el suero antidiftérico "nuncio» de la nueva medicina», Dynamis, 27, 33-44.

Rodríguez-Ocaña, E. (2014). «Eduardo Gallardo Martínez y los inicios de la virología científica en España», en Campos, Ricardo et al. (eds.). Medicina y política. Madrid: SEHM y Facultad de Medicina de la Universidad Complutense, pp. 467- 472 .

Rodríguez-Ocaña, E. (2017). «Ocaso de la Medicina Social en España: el caso de la leptospirosis,» Asclepio, 62 (2), 199.

Rodríguez-Ocaña, E. y Atenza Fernández, J. (2019). «El proyecto E30 OMS-España para el establecimiento de una zona de demostraciones sanitarias en Talavera de la Reina, 1965-1976», en Porras Gallo, M. I., Mariño, L. y Caballero, M. V. (eds.). Salud, enfermedad y medicina en el franquismo. Madrid: Los Libros de la Catarata, pp. 124-145.

Sales Vázquez, R. (1955). «Poliomielitis, epidemiología y profilaxis. A propósito del brote epidémico de 1954 en Barcelona», Anales de Medicina y Cirugía, 35 (121-122), 231-267.

Tapia Martínez, M. (1930a). «Estudio clínico de la epidemia de poliomielitis de Madrid en 1929", La Medicina Ibera, 652, 621-628.

Tapia Martínez, M. (1930b). «Estudio clínico de la epidemia de poliomielitis de Madrid en 1929», La Medicina Ibera, 653, 657-663.

Théodoridés, J. (1974). "La microbiología médica», en Laín Entralgo, P. (dir) Historia Universal de la Medicina. Barcelona: Salvat, vol.6, pp. 175-192.

Weindling, P. (1993). «Public health and the political stabilization. The Rockefeller Foundation in Central and Eastern Europe between the Two World Wars", Minerva 31, 253-267.

Weindling, P. (1995). International health organizations and movements. New York: Cambridge University Press. 